\title{
SELECTED ASPECTS OF THE KNOWLEDGE AND PRACTICE CONCERNING HAND HYGIENE GUIDELINES IN THE CONTEXT OF INFECTION CONTROL STRUCTURES IN HOSPITALS AND LONG-TERM CARE FACILITIES - FINDINGS OF A QUESTIONNAIRE SURVEY
}

\author{
Grażyna Puto ${ }^{1}$, Jadwiga Wójkowska-Mach², Marta Wałaszek³ ${ }^{3}$ Iwona Repka ${ }^{1}$, Anna Różańska \\ ${ }^{1}$ Jagiellonian University Medical College, Kraków, Poland \\ Faculty of Health Sciences, Institute of Nursing and Midwifery, Department of Clinical Nursing \\ 2 Jagiellonian University Medical College, Kraków, Poland \\ Faculty of Medicine, Chair of Microbiology \\ ${ }^{3}$ State Higher Vocational School, Tarnów, Poland \\ Health Department
}

\begin{abstract}
Background: Hand hygiene $(\mathrm{HH})$ is the simplest and the most fundamental means of hospital-acquired infection (HAI) prevention in both hospitals and long-term care facilities (LTCFs) which differ as to their structure, organization and epidemiology. The objective of this study was to evaluate the knowledge of, and attitudes towards, compliance with the $\mathrm{HH}$ guidelines by medical staff of LTCFs and hospitals, in the context of infection control organization. Material and Methods: The study was carried out among medical staff of LTCFs and hospitals using an anonymous questionnaire designed by the authors. The questionnaire was composed of 22 questions. Results: Among 237 healthcare workers from LTCFs and hospitals (51.5\% vs. 48.5\%), the vast majority were women $(97.5 \%$ vs. $94.8 \%)$, who were nurses $(86.9 \%$ vs. $91.3 \%)$ with $21-30$ years of experience $(28.5 \%$ vs. $44.3 \%)$. The respondents, both working in hospitals and in LTCFs, declared that there was some surveillance of HAIs in their workplace - 78.8\% vs. $87.8 \%$, respectively, $\mathrm{p}=0.082$. However, the respondents from LTCFs significantly more often than those working in hospitals declared the lack of HAI registration $(12.3 \%$ vs. $0.9 \%, \mathrm{p}=0.002)$, as well as the lack of surveillance of multidrug-resistant microorganisms $(16.4 \%$ vs. $4.3 \%, \mathrm{p}=0.010)$. Although the knowledge of $\mathrm{WHO} \mathrm{HH}$ guidelines was declared by over $90 \%$ of the respondents, only about $70 \%$ of them (with no significant difference between both types of facilities) properly indicated the 5 moments of HH. Conclusions: The results of the study indicate that the organizational conditions and practice of HH in LTCFs and hospitals present some differences. Therefore, there is a need for observational studies concerning $\mathrm{HH}$ in the context of the structure and organization of infection control, as they are necessary for the development and implementation of effective programs to improve the situation in this field. Med Pr. 2020;71(5):531-7
\end{abstract}

Key words: knowledge, practice, hospital, hand hygiene, infections, long-term care

Corresponding author: Grażyna Puto, Jagiellonian University Medical College, Faculty of Health Sciences, Institute of Nursing and Midwifery, Department of Clinical Nursing, Kopernika 35, 31-501 Kraków, Poland, e-mail: grazyna.puto@uj.edu.pl Received: February 27, 2020, accepted: June 8, 2020

\section{INTRODUCTION}

Medical staff face a major challenge of caring for the health and lives of patients, while also bearing the responsibility for preventing infections not only in hospitals but in long-term care facilities (LTCFs) as well. The importance of this task is highlighted by the fact that infection prevention is one of the topmost priorities of modern medicine. According to experts, in developed countries, depending on the form of infection and on the population, up to a third of healthcare-associated infections could be avoided by comply- ing with hygiene recommendations or by implementing new solutions among practitioners [1].

Hand hygiene $(\mathrm{HH})$ of medical workers, the promotion of which is treated as a global priority in the fight against infections, is the simplest and the most effective method of preventing infections in healthcare facilities. The World Health Organization (WHO) recommends that $\mathrm{HH}$ be implemented according to a 6-step Ayliffe technique in specific medical situations, referred to as "My 5 moments for HH." In the Ayliffe technique, the order of subsequent steps ensures that the hands are thoroughly decontaminated, as it eliminates the risk 
of skipping some areas of the hands in the process of washing and disinfecting them. The ability to apply this technique in accordance with the guidelines concerning the 5 moments for $\mathrm{HH}$ is recognized as the most important basic element of infection prevention [2]. The organization and practice of infection control in LTCFs other than hospitals has resulted in the European Centre for Disease Prevention and Control (ECDC) carrying out projects dedicated to assessing the epidemiological situation and organizing infection control in these facilities. Point prevalence studies (PPS) are conducted in hospitals, while in other facilities the monitoring tool is the Healthcare Associated Infections in Long-Term Care Facilities (HALT) program, both of which are carried out in most European countries, including Poland. The programs obtain the necessary information about clinical forms of infections, etiological factors, antibiotic consumption, as well as selected indicators of the structure and control processes of these infections (including those regarding infection control staff or the use of alcohol-based hand sanitizers) in these facilities [3].

The obtained results allow for a better interpretation of epidemiological factors, and for an improved planning and organization of infection control. Yet those results are still characterized by a high level of generality (e.g., in relation to $\mathrm{HH}$, they do not provide information whether the procedures used are in accordance with the guidelines and whether the medical staff possess an appropriate knowledge in this area). To obtain a comprehensive picture in this regard, it is necessary to conduct more detailed research. The main goal of the study was to assess hospital staff's knowledge of, and attitudes towards, $\mathrm{HH}$ procedures in the daily practice of LTCFs and hospitals in relation to selected infection control structures and process indicators.

\section{MATERIAL AND METHODS}

The survey was carried out in March-June 2018 in accordance with the principles contained in the Helsinki Declaration [4]. The study was based on the diagnostic survey method, and the research tool was a questionnaire containing 22 questions developed by the authors. The questionnaire was distributed among the personnel, mainly nurses working in LTCFs or hospitals, during postgraduate courses organized by regional Chambers of Nurses and during two 1-day training meetings dedicated to infection control. All the respondents filled in the questionnaire personally.
The questionnaire contained written information about the purpose of the study; it also specified that the survey was anonymous and that providing personal information was voluntary. Questions 1-6 covered the general characteristics of healthcare workers, i.e., work experience, occupation (doctor, nurse/midwife, medical carer), workplace, i.e., LTCFs (various kinds of care and treatment centers) vs. hospitals (wards such as internal medicine, geriatric, neurology, cardiology), and the type of the facility (state-owned, private). No data were collected that could enable the identification of particular facilities (hospital or LTCF).

Questions included in the survey concerned the following issues:

- the existence of infection control programs (taking into account multidrug-resistant organisms [MDROs]) in the facility, personnel involved in infection prevention and control (infection control structures and process indicators);

the knowledge of the 5 moments for $\mathrm{HH}$ (yes/no) and a task that consisted in listing each of the moments, giving an opinion on $\mathrm{HH}$ compliance by healthcare workers, and a self-assessment of $\mathrm{HH}$ compliance carried out by the respondents;

- checking the compliance with $\mathrm{HH}$, including both the Ayliffe technique and the 5 moments for $\mathrm{HH}$ as recommended by WHO, in the facility (the infection control process indicator);

assessing the importance of given factors (such as education, the use of protective gloves, $\mathrm{HH}$, waste disposal) in hospital-acquired infection (HAI) prevention, combined with assigning them a level of importance from 1 (unimportant) to 5 (the most important);

the rules and difficulties in complying with $\mathrm{HH}$, where the respondents were also asked to indicate the factors that encourage medical staff to increase the monitoring of the technique and the frequency of $\mathrm{HH}$, as well as the surveillance of infections.

The statistical analysis of the obtained test results was performed using IBM SPSS Statistics v. 24 for Windows. Distributions of qualitative variables are presented in the form of absolute [n] and relative [\%] numbers of individual categories. The relationship between qualitative variables was analyzed using Pearson's $\chi^{2}$ test when at most $20 \%$ of the cells had an expected number of $<5$; otherwise Fisher's exact test for $2 \times 2$ tables, and the Fisher-Freeman-Halton test for tables of other dimensions were used. In all the analyses performed, the existence of differences and the strength of the rela- 
tionship between the variables was estimated at a significance level of $\mathrm{p}<0.05$.

The study was conducted with the consent of the Bioethics Committee of the Jagiellonian University, No. KBET/122.6120.124.2016.

\section{RESULTS}

Overall, 237 respondents were surveyed, including LTCF and hospital workers ( $51.5 \%$ vs. $48.5 \%)$, and the vast majority were women $(97.5 \%$ vs. $94.8 \%)$, nurses $(86.9 \%$ vs. $91.3 \%)$ with $21-30$ years of experience ( $28.5 \%$ vs. $44.3 \%)$, working in state-owned facilities ( $89.3 \%$ vs. $86.1 \%)$. Detailed characteristics of the study group is presented in Table 1.

The respondents declared that, both in LTCFs and in hospitals in which they worked, there were some designated officials responsible for handling healthcare-associated infections $(78.7 \%$ vs. $87.8 \%, \mathrm{p}=0.082)$. Those facilities were significantly more often state-owned than private $(88.5 \%$ vs. $44.8, \mathrm{p}<0.001)$. A comparable percentage of respondents working in LTCFs and in hospitals indicated the presence of an epidemiological nurse in the workplace ( $85.2 \%$ vs. $84.3 \%)$, and only a small proportion indicated the presence of an infection control team (LTCFs $-8.2 \%$, hospitals $-10.4 \%$ ) or an infection control committee (LTCFs - 5.7\%, hospitals 5.2\%). According to the respondents, epidemiological nurses in most LTCFs and hospitals conducted infection control independently ( $83.6 \%$ vs. $92.2 \%)$, while in a few facilities they cooperated with doctors $(10.7 \%$ vs. $6.1 \%)$ or with microbiologists $(2.5 \%$ vs. $1.7 \%)$.

Medical staff of LTCFs declared significantly more often than hospital staff that health-related infections were not registered in the workplace $(12.3 \%$ vs. $0.9 \%$, $\mathrm{p}=0.002)$, and that there was no surveillance of MDROs ( $16.4 \%$ vs. $4.3 \%, \mathrm{p}=0.010)$. The knowledge of the guidelines regarding the 5 moments for $\mathrm{HH}$, as recommended WHO, was declared by both hospital and LTCF workers (93\% vs. 91\%, p = 0.559). The HH knowledge of medical staff, including hygienic hand washing or disinfection, appears to be insufficient regarding the 5 moments for HH among both LTCF and hospital workers. None of the 5 moments was indicated correctly by $100 \%$ of the respondents, and the moment before clean/aseptic procedure was indicated by only $57.4 \%$ of the respondents from LTCFs and by $67.8 \%$ from hospitals (Table 2).

The respondents were asked whether, according to their experience, medical staff sometimes do not com-
Table 1. Demographic characteristics of medical staff of long-term care facilities (LTCFs) and hospitals according to their workplace, in the survey carried out in March-June 2018

\begin{tabular}{|c|c|c|c|}
\hline \multirow[t]{2}{*}{ Variable } & \multicolumn{2}{|c|}{$\begin{array}{l}\text { Healthcare workers } \\
{[\mathrm{n}(\%)]} \\
(\mathrm{N}=237)\end{array}$} & \multirow[t]{2}{*}{$\mathrm{p}$} \\
\hline & LTCF & hospital & \\
\hline Gender & & & $0.322^{*}$ \\
\hline women & $119(97.5)$ & $109(94.8)$ & \\
\hline men & $3(2.5)$ & $6(5.2)$ & \\
\hline Profession & & & $0.082^{* *}$ \\
\hline physician & $0(0.0)$ & $2(1.7)$ & \\
\hline nurse & $106(86.9)$ & $105(91.3)$ & \\
\hline other (physiotherapist, etc.) & $16(13.1)$ & $8(7.0)$ & \\
\hline Work experience & & & $0.741^{* * *}$ \\
\hline $0-10$ years & $29(23.8)$ & $25(21.7)$ & \\
\hline $11-20$ years & $30(24.6)$ & $28(24.3)$ & \\
\hline $21-30$ years & $47(28.5)$ & $51(44.3)$ & \\
\hline$>30$ years & $16(13.1)$ & $11(9.6)$ & \\
\hline Facility type & & & $0.444^{* * *}$ \\
\hline state-owned & $109(89.3)$ & $99(86.1)$ & \\
\hline private & $13(10.7)$ & $16(13.9)$ & \\
\hline
\end{tabular}

${ }^{*} \mathrm{p}$-value for Fisher's exact test, ${ }^{* *} \mathrm{p}$-value for Pearson's $\chi^{2}$ test, ${ }^{* * *} \mathrm{p}$-value for asymptomatic Pearson's $\chi^{2}$ test.

ply with the $\mathrm{HH}$ guidelines. More than half of the surveyed LTCF and hospital workers answered "never," while, according to the self-assessment of long-term care personnel, it is significantly "often" that they do not comply with the $\mathrm{HH}$ guidelines compared to hospital staff (Table 3).

In LTCFs, as indicated by the respondents, the superiors significantly more often than in hospitals checked whether hand disinfection was carried out with a frequency adequate to the 5 moments for $\mathrm{HH}(71.3 \%$ vs. $54.8 \%, \mathrm{p}=0.020)$, and whether the correct Ayliffe technique in the workplace was implemented $(72.1 \%$ vs. $56.5 \%, \mathrm{p}=0.020$ ).

The vast majority of LTCF and hospital staff do not face difficulties in implementing the $\mathrm{HH}$ guidelines in contact with the patient ( $75.4 \%$ vs. $68.7 \%)$, while hospital staff more often than LTCF workers declared that they face such difficulties ( $31.3 \%$ vs. $24.6 \%, \mathrm{p}=0.249)$. The most frequently indicated difficulty by both LTCF and hospital staff was the lack of time $(93.4 \%$ vs. $88.7 \%$, $\mathrm{p}=0.199)$, staff shortages $(99.2 \%$ vs. $96.5 \%, \mathrm{p}=0.155)$, and a shortage of resources for disinfection (17.2\% vs. $13.9 \%, p=0.484)$. 
Table 2. Selected process indicators of infection control, respondents' knowledge of WHO's 5 moments for hand hygiene (HH) and declarations of the $\mathrm{HH}$ compliance check in long-term care facilities (LTCFs) and hospitals, in the survey carried out in March-June 2018

\begin{tabular}{|c|c|c|c|c|}
\hline \multirow[t]{2}{*}{ Variable } & \multicolumn{2}{|c|}{$\begin{array}{c}\text { Facility } \\
{[\mathrm{n}(\%)]} \\
(\mathrm{N}=237)\end{array}$} & \multirow{2}{*}{$\mathrm{p}$} & \multirow[t]{2}{*}{ OR $(95 \% \mathrm{CI})$} \\
\hline & $\begin{array}{c}\text { LTCF } \\
(\mathrm{N}=122)\end{array}$ & $\begin{array}{l}\text { hospital } \\
(\mathrm{N}=115)\end{array}$ & & \\
\hline Healthcare-associated infections registration in the workplace (yes) & $99(81.1)$ & $107(93.0)$ & 0.002 & $0.3(0.13-0.75)$ \\
\hline Surveillance of multidrug-resistant microorganisms (yes) & $78(63.9)$ & $82(71.3)$ & 0.010 & $0.7(0.41-1.23)$ \\
\hline \multicolumn{5}{|l|}{ Knowledge of WHO's 5 moments for $\mathrm{HH}$} \\
\hline before touching a patient & $87(71.3)$ & $83(72.2)$ & 0.8 & $0.9(0.54-1.69)$ \\
\hline before clean/aseptic procedures & $87(71.3)$ & $84(73.0)$ & 0.77 & $0.9(0.52-1.62)$ \\
\hline before clean/aseptic procedures & $70(57.4)$ & $78(67.8)$ & 0.097 & $0.6(0.39-1.09)$ \\
\hline after touching a patient & $89(73.0)$ & $85(73.9)$ & 0.87 & $0.9(0.53-1.69)$ \\
\hline after touching patient's surroundings & $109(89.3)$ & $105(91.3)$ & 0.61 & $0.8(0.33-1.9)$ \\
\hline $\mathrm{HH}$ compliance check with the guidelines for the 5 moments of $\mathrm{HH}$ & $87(71.3)$ & $63(54.8)$ & 0.02 & $2.1(1.19-3.51)$ \\
\hline HH compliance check with the Ayliffe technique & $88(72.1)$ & $65(56.5)$ & 0.02 & $2.0(1.16-3.42)$ \\
\hline
\end{tabular}

p-value for Pearson's $\chi^{2}$ test.

Table 3. Respondents' opinions on other medical staff and their own compliance with the hand hygiene $(\mathrm{HH})$ guidelines in long-term care facilities (LTCFs) and hospitals, in the survey carried out in March-June 2018

\begin{tabular}{lccc}
\hline \multirow{2}{*}{ Respondents' opinions } & \multicolumn{2}{c}{ Facility } & \\
\cline { 2 - 3 } & LTCF & hospital & \\
\cline { 2 - 3 } $\begin{array}{l}\text { Failure to comply with HH } \\
\text { by medical staff }\end{array}$ & & & \multirow{2}{*}{0.480} \\
always & $6(4.9)$ & $10(8.7)$ & \\
often & $35(28.7)$ & $35(30.4)$ & \\
sometimes & $8(6.6)$ & $4(3.5)$ & \\
never & $73(59.8)$ & $66(57.4)$ & \\
Self-assessment: & & & \\
I skip HH procedures & & & \\
always & 0.042 \\
often & $12(9.9)$ & $3(2.6)$ & \\
sometimes & $77(63.1)$ & $81(70.4)$ & \\
never & $33(27.0)$ & $29(25.2)$ & \\
\hline
\end{tabular}

p-value for Pearson's $\chi^{2}$ test.

Among the most important measures to prevent the occurrence of healthcare-associated infections (the use of disposable gloves, the isolation of patients, the disinfection of equipment, $\mathrm{HH}$, compliance with asepsis techniques, proper waste sorting, change of work clothing, education of medical staff), the highest rank was assigned by LTCF staff to equipment disinfection $(64.8 \%$ vs. $66.1 \%, p=0.012)$ and adherence to aseptic techniques $(76.2 \%$ vs. $75.7 \%, p=0.001)$, while hospital workers chose increased education of medical staff ( $66.1 \%$ vs. $57,4 \%, \mathrm{p}=0.029$ ).

\section{DISCUSSION}

The study conducted among medical staff of LTCFs found that the respondents declared the presence of personnel conducting infection control in the workplace. The practice of registering infections, and in particular the surveillance of MDROs, was significantly less frequently confirmed in LTCFs than in hospitals. Unfortunately, the review of the literature confirms the above data: in Polish LTCFs, there is no ongoing surveillance of infections, with the simultaneous lack of epidemiological and microbiological monitoring. The only small multicenter study that was carried out in 2009-2010 found that the incidence (at 2.7/1000 mandays) was slightly lower than expected [5]. In the same study, the prevalence of methicillin-resistant staphylococci (infection and colonization) was 17.6\% [6], and E. coli producing extended-spectrum beta-lactamases (ESBL) - 13.9\% in asymptomatic bacteriuria [7], which was a high rate. Thus, the authors' assessment of HAIs and MDROs in LTFCs allowed them to draw the conclusion that surveillance was being carried out in the fa- 
cilities. However, this view was probably based on overly optimistic assumptions, and was thus not entirely credible. This is because patients in LTCFs especially the elderly and those with multiple diseases and significant psychophysical disability, require increased care, which results in the increased risk of HAIs and MDROs.

The most common infections in this group of people are pneumonia $(5.7 \%-1.1 \%$ prevalence $)$ and urinary tract infections (2.6\% - 0.5\% prevalence) [8], most often caused by ESBL-producing enterobacteriaceae [9]. Also, other MRDOs may pose a problem in LTCFs, including the development of carbapenem-resistant enterobacteriaceae [10].

As for the epidemiology of infections in LTCFs, another important form of infections are clostridioides difficile infections whose incidence is recorded at 4.41/10 000 man-days. These values are similar to those obtained among patients hospitalized in departments other than intensive care units [11]. Those values, unlike the examples above, represent infections with a high risk of spreading. Therefore, training concerning surveillance and infection prevention, with particular emphasis on $\mathrm{HH}$, is an important element of infection control programs. The result should not only be knowledge, but also practical compliance by healthcare professionals.

The respondents of this study, mostly nurses, gave correct answers to the question related to the $5 \mathrm{mo}$ ments for $\mathrm{HH}$ more often than doctors in the study conducted by Wałaszek et al. [12]. The moment before touching the patient is especially noteworthy, as it was emphasized in this study by about $70 \%$ of the respondents. Meanwhile, in the study by Wałaszek et al. only about $55 \%$ of doctors, $59 \%$ of medical students undergoing internships, and $80 \%$ of interns paid attention to this element. A much higher percentage of correct answers was obtained in the present study in comparison with the results of the study by Wałaszek et al., with respect to the moment after exposure to body fluids or after contact with the patient's immediate surroundings.

Worse results in the present study were recorded in the case of a self-assessment and assessment of compliance with the $\mathrm{HH}$ guidelines by other medical staff. In this study, as many as $60 \%$ of the respondents declared that medical staff adhered to the principles of $\mathrm{HH}$ despite the fact that in the self-assessment part only $25 \%$ of hospital workers and $27 \%$ of LTCF workers made such a declaration. In other studies concerned with this subject, very diverse responses were noted. For example, in an analysis conducted among medical students, only $20-30 \%$ of the respondents declared that medical personnel adhered to the $\mathrm{HH}$ guidelines [13,14]. In a study carried out in 2014 among medical students, it was found that $30-50 \%$ of medical workers complied with the HH guidelines [15]. Such answers were more often given by first-year students, and with the increase of clinical experience (internship or work), the percentage of these answers decreased.

According to reports, the results of studies carried out abroad regarding the $\mathrm{HH}$ guidelines found that the rate of adherence to these guidelines reached a level of $>50 \%$, with an indication of its increase after intervention programs [16-19]. There are few reports in academic literature concerning research in Poland. Most of the research conducted so far has been selective. When investigating the correctness of the Ayliffe technique as performed by doctors and medical students, in a study conducted by Wałaszek et al. [12], compliance below $30 \%$ (in the range of 3.1-28.1\%) was observed over several years. The relatively critical self-assessment of compliance with the $\mathrm{HH}$ guidelines by the participants of this study suggests that the given answers are probably reliable.

In the analysis of the results of the study carried out by Wałaszek et al. [12], only $28 \%$ of the participants declared that their application of the guidelines of the 5 moments for $\mathrm{HH}$ had been verified. The verification allowed the researchers to obtain results which in $64 \%$ of cases proved the personnel's correct performance of $\mathrm{HH}$ by the Ayliffe technique. The results of this study may seem surprising in this respect; firstly, about $55 \%$ of the respondents working in hospitals and over $70 \%$ of LTCF workers reported that the supervisor monitored the application of $\mathrm{HH}$ procedures at least once (ever), in terms of their compliance with the 5 moments for $\mathrm{HH}$ and the Ayliffe technique. Questions about surveillance in this regard were significantly more often given an affirmative answer by medical staff of LTCFs than by hospital staff. The explanation for this observation can be either the fact that superiors do not consider $\mathrm{HH}$ a matter worth verifying, or that their knowledge and skills regarding $\mathrm{HH}$ are insufficient. Both of these hypotheses are confirmed in the research by Rosiński et al. [14] that highlights the significant impact of many years of seniority on the perception of the rules of standard isolation, of which $\mathrm{HH}$ is an essential element.

On the other hand, the reasons for non-compliance with the $\mathrm{HH}$ guidelines, as indicated by the respondents of the study (about a quarter of them), were similar to those mentioned by participants in other Polish 
studies. The main reasons for non-compliance include the lack of time, staff and hygiene products [12,15], despite the fact that about $75.4 \%$ of LTCF workers and $68.7 \%$ of hospital workers declared that they did not encounter any difficulties in implementing the $\mathrm{HH}$ guidelines. Similar results were obtained in a study carried out in Germany by Hammersschmidt and Manser [20] regarding the knowledge and attitudes of long-term care nurses, where about $70 \%$ of the respondents declared that they had personal protective equipment, and over $80 \%$ confirmed the availability of $\mathrm{HH}$ preparations. However, the respondents in the German study declared more often (56\%) that they always had the opportunity to carry out $\mathrm{HH}$ procedures when working with patients.

The results of this study, which aimed to compare the knowledge of HH in LTCFs to its level among hospital staff, are surprising. This is due to the fact that, on the one hand, according to the respondents' declarations, infection control and surveillance of MDROs are carried out less frequently in the LTCFs than in hospitals, but, on the other hand, the knowledge of the 5 moments for $\mathrm{HH}$ is similar among medical staff of both types of facilities, although their practical application was more often verified in LTCFs. Therefore, the problem of infection control and prevention, including compliance with the $\mathrm{HH}$ guidelines, in the context of organizational conditions in both types of facilities, requires an intervention in order to effectively implement WHO guidelines. It is necessary to carry out additional and more detailed research as well.

\section{CONCLUSIONS}

According to the respondents, the control of healthcare-associated infections and the surveillance of MDROs was more often carried out in hospitals than in LTCFs.

Both LTCF and hospital staff presented a similar unsatisfactory level of knowledge regarding the 5 moments for $\mathrm{HH}$.

In hospitals as well as in LTCFs, interventions are necessary to promote the $\mathrm{HH}$ guidelines in accordance with WHO recommendations. There is a need for observational studies on $\mathrm{HH}$ practice in the context of the structure and organization of infection control. Such research is vital for the development and implementation of effective programs aimed at improving the situation in this field.

\section{REFERENCES}

1. Zacher B, Haller S, Willrich N, Walter J, Abu Sin M, Cassini A, et al. Application of a new methodology and $\mathrm{R}$ package reveals a high burden of healthcare-associated infections (HAI) in Germany compared to the average in the European Union/European Economic Area, 2011 to 2012. EuroSurveill. 2019;24(46), https://doi.org/10.2807/ 1560-7917.ES.2019.24.46.1900135.

2. World Health Organization [Internet]. Geneva: The Organization; 2009 [cited 2019 Sept 30]. Guidelines on Hand Hygiene in Health Care. First. Global Patient Safety Challenge. Clean Care is Safer Care. WHO Press, Geneva 2009. Available from: https://apps.who.int/iris/bitstream/ handle/10665/44102/9789241597906_eng.pdf;jsession$\mathrm{id}=6 \mathrm{E} 12 \mathrm{BEDEBAD} 86 \mathrm{AFADA} 12 \mathrm{A06C7B5679EF}$ ?sequence $=1$.

3. Suetens C, Latour K, Karki T, Ricchizzi E, Kinross P, Moro ML, et al. Prevalence of healthcare-associated infections, estimated incidence and composite antimicrobial resistance index in acute care hospitals and long-term care facilities: results from two European point prevalence surveys, 2016 to 2017. EuroSurveill. 2018;23(46), https://doi. org/10.2807/1560-7917.ES.2018.23.46.1800516.

4. World Medical Association [Internet]. Geneva: The Organization; 2013 [cited 2018 July 9]. World Medical Association Declaration of Helsinki Ethical Principles for Medical Research Involving Human Subjects. Available from: https:// www.wma.net/policies-post/wma-declaration-of-helsinki-ethical-principles-for-medical-research-involving-human-subjects/.

5. Wójkowska-Mach J, Gryglewska B, Czekaj J, Adamski P, Grodzicki T, Heczko PB. Infection control: point prevalence study versus incidence study in Polish long-term care facilities in 2009-2010 in the Małopolska Region. Infection. 2013;41(1):1-8, https://doi.org/10.1007/s15010012-0351-5.

6. Romaniszyn D, Pobiega M, Wójkowska-Mach J, Chmielarczyk A, Gryglewska B, Adamski P, et al. The general status of patients and limited physical activity as risk factors of Methicillin-resistant Staphylococcus aureus occurrence in long-term care facilities residents in Krakow, Poland. BMC Infect Dis. 2014;14:271, https://doi.org/10.1186/1471-233414-271.

7. Pobiega M, Wojkowska-Mach J, Chmielarczyk A, Romaniszyn D, Adamski P, Heczko PB, et al. Molecular characterization and drug resistance of Escherichia coli strains isolated from urine from long-term care facility residents in Cracow, Poland. Med Sci Monit. 2013;19:317-26, https:// doi.org/10.12659/MSM.883898. 
8. Nicolle LE. Infection prevention issues in long-term care. Curr Opin Infect Dis. 2014;27(4):363-9, https://doi. org/10.1097/QCO.0000000000000071.

9. Giufrè M, Accogli M, Ricchizzi E, Barbanti F, Farina C, Fazii $\mathrm{P}$, et al. Multidrug-resistant infections in long-term care facilities: extended-spectrum $\beta$-lactamase-producing Enterobacteriaceae and hypervirulent antibiotic resistant Clostridium difficile. Diagn Microbiol Infect Dis. 2018;91(3):275-81, https://doi.org/10.1016/j.diagmicrobio. 2018.02.018.

10. Henig O, Cober E, Richter SS, Perez F, Salata RA, Kalayjian RC, et al. A Prospective Observational Study of the Epidemiology, Management, and Outcomes of Skin and Soft Tissue Infections Due to CarbapenemResistant Enterobacteriaceae. Open Forum Infect Dis. 2017;4(3):ofx157, https://doi.org/10.1093/ofid/ofx157.

11. Balsells E, Shi T, Leese C, Lyell I, Burrows J, Wiuff C, et al. Global burden of Clostridium difficile infections: a systematic review and meta-analysis. J Glob Health. 2019;9(1):010407, https://doi.org/10.7189/jogh.09.010407.

12. Wałaszek M, Kołpa M, Wolak Z, Różańska A, WójkowskaMach J. Poor Hand Hygiene Procedure Compliance among Polish Medical Students and Physicians The Result of an Ineffective Education Basis or the Impact of Organizational Culture? Int J Eviron Res Public Health 2017;14(9), https://doi.org/10.3390/ijerp14091026.

13. Feather A, Stone SP, Wessier A, Boursicot KA, Pratt C. "Now please wash your hands": The handwashing behaviour of final MBBS candidates. J Hosp Infect. 2000; 45(1):62-4, https://doi.org/10.1053/jhin.1999.0705.

14. Paotong D, Trakarnachansiri J, Phongsanon K, Churncharoen P, Sitphong S, Poldee T, et al. Compliance with handwahsing in a university hospital in Thailand.
Am J Infect Control. 2003;31:128, https://doi.org/10.1067/ mic.2003.37.

15. Różańska A, Wójkowska-Mach J, Bulanda M. [Work experience and seniority in health care vs. medical students' knowledge of selected hand hygiene procedures]. Med Pr. 2016;67(5):623-33, https://doi.org/10.13075/mp. 5893.00440. Polish.

16. Reichardt C, Königer D, Bunte-Schönberger K, van der Linden P, Mönch N, Schwab F, et al. Three years of national hand hygiene campaing in Germany: what are the key conslusions for clinical practice? J Hosp Infect. 2013;83(1):11-6, https://doi.org/10.1016/S0195-6701(13) 60004-3.

17. Pittet D, Allegranzi B, Boyce J. The World Health Organization guidelines on hand hygiene in health care and their consensus recommendations. Infect Control Hosp Epidemiol. 2009;30(7):611-22, https://doi.org/10. 1086/600379.

18. Grayson ML, Russo PL, Cruickshank M, Bear JL, Gee CA, Hughes CF, et al. Outcomes from the first two years of the Australian national hand hygiene initiative. Med J Aust. 2011;195(10):615-9, https://doi.org/10.5694/mja11. 10747.

19. Keller J, Wolfensberger A, Clack L, Kuster SP, Dunic M, Eis D, et al. Do wearable alcohol-based handrub dispensers increase hand hygiene compliance? - a mixed-methods study. Antimicrob Res Infect Control. 2018;7:143, https://doi.org/10.1186/s13756-018-0439-5.

20. Hammerschmidt J, Manser T. Nurses' knowledge, behavior and compliance concerning hand hygiene in nursing homes: a cross-sectional mixed-methods study. BMC Health Serv Res. 2016;19(1):547, https://doi.org/10.1186/ s12913-019-4347-z.

This work is available in Open Access model and licensed under a Creative Commons Attribution-NonCommercial 3.0 Poland License - http://creativecommons.org/licenses/by-nc/3.0/pl/deed.en. 